\title{
CHARACTERIZATION AND REJUVENATION OF LOCAL ECORACE SUKINDA IN ODHISA STATE
}

\author{
Alok Sahay, Subrat Satpathy* and S.K. Sharan, \\ Regional Tasar Research Station, Ministry of Textiles, Govt of India, Palbani, \\ Baripada-757 001, Odhisa.
}

*Working at Research Extension Center, Bangriposi

Tropical tasar flora and fauna are abundantly distributed in the peninsular forest of Central India boarded by major rivers viz Ganga in the North, Godavari in the South, Mahanadi in the East and Wainganga in the west. Owing to the wide range of dispersal of silkworm, Antheraea mylitta D. in India, the species have encountered varied geographical conditions and have formed ecological populations (ecoraces) in varied geography, topography, ecology, food plant flora and frequency of life cycle of the silk moths in latitudinal and altitudinal gradients. These ecoraces exhibit diversity in phenotypic behavior, physio-genetic and commercial characters. These variations are genetic treasure, the conservation, maintenance and protection of which are most important for their qualitative and quantitative improvement as a whole.

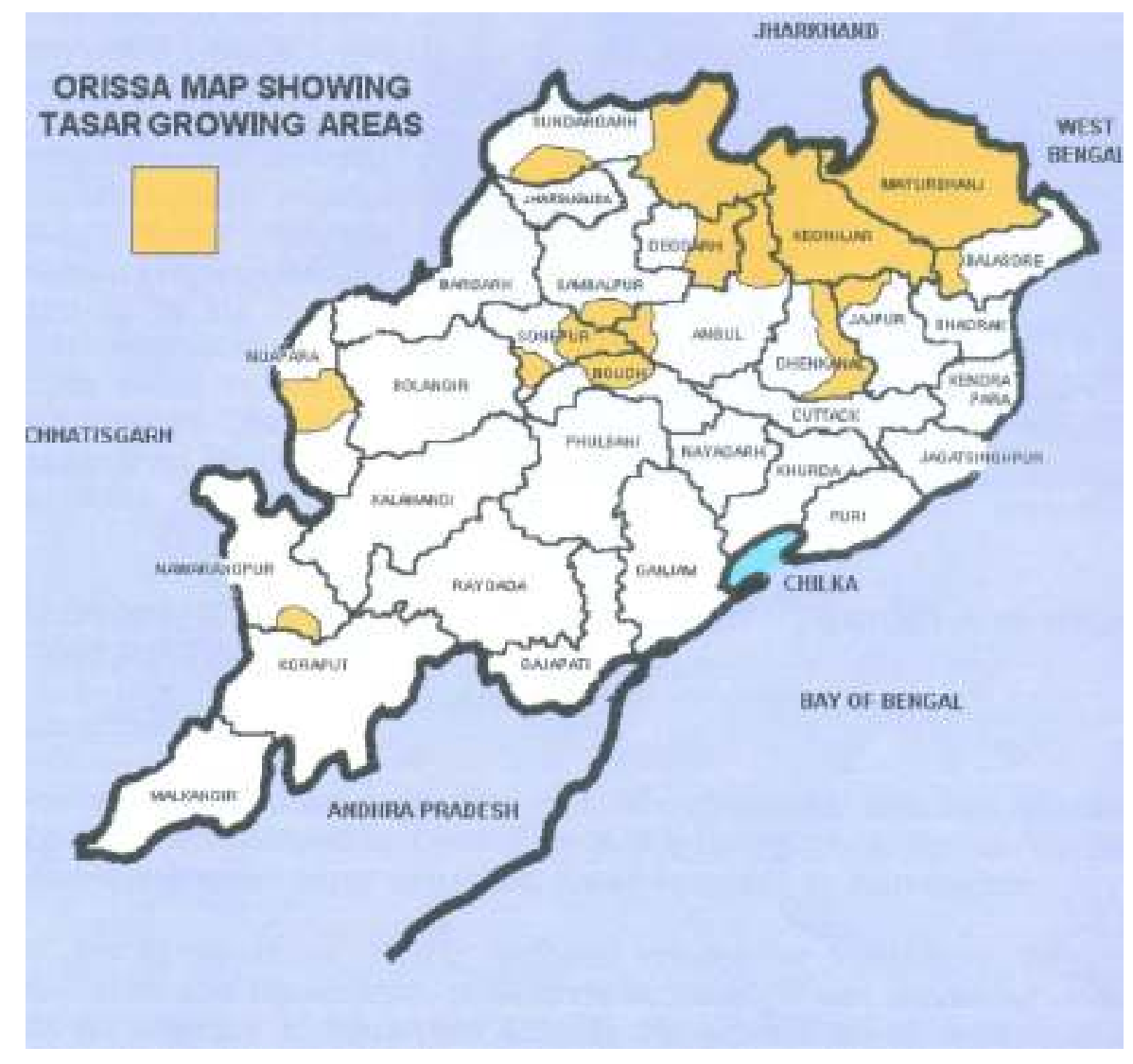

Fig-1 Map of Orissa showing tasar culture area. 
The forty four ecoraces of Antheraea mylitta (Srivastava et al., 2002, 2003, 2004; Suryanarayana and Srivastava, 2005; Thangavelu et al.,2002) have been identified through survey, collection and exploration in different states of tropical India.

These ecoraces breed better and maintain their physical and genetic characters in their natural habitat, the forest. An ecorace, collected from Kunda, Ankurapal ,Sukaran and Kans area of Sukindagarh $\left(85.62^{\circ} \mathrm{N}\right.$ and $\left.20.88^{\circ} \mathrm{E}\right)$ of Jajpur district of Orissa, known as Sukinda ecorace was introduced to other areas by the state Department of Sericulture and was commercially cultivated during 1970s. The race being trivoltine was suitable for warmer climates, cocoons were predominately yellow with Silk Ratio ranging between 10.5 to13.1\% in different seasons and fared well in semi-domesticated conditions. It had also advantages over the wild tasar races in low pupal mortality during preservation, higher coupling and cocoon:dfl ratio and less deterioration of economic characters in progenies.

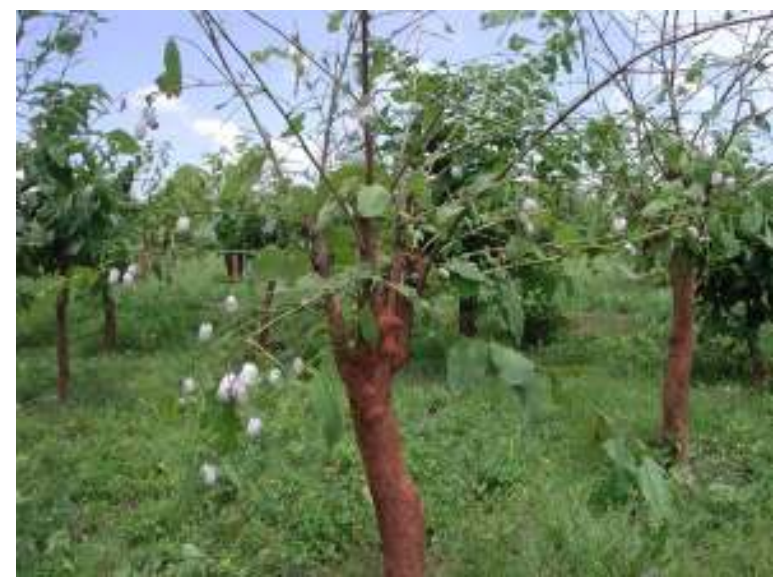

Fig-2 Sukinda Cocoons are ready to be harvested.

An experiment of outdoor rearing was conducted with the available Sukinda (TV) stock of BSM\&TC, Sundargarh (SG), CTSSS, Lakha (CTS) and CTR\&TI, Ranchi. The objective of this activity is to utilize economic wild life, conserving the associated environment for sustainable rural and tribal development (Raffi and Ramanujam, 2001; Gill and Lal, 2002; Mahapatra, 2009).

The crop performance of SG showed highest cocoon yield i.e., 83 cocoons / dfl in $1^{\text {st }}$ crop followed by 80 cocoons / dfl in $3^{\text {rd }}$ crop and 42 cocoons / dfl during $2^{\text {nd }} \mathrm{crop}$. Yellow coloured cocoons dominated (94-96\%) the population in all the three crops. The cocoon weight, Shell weight and Silk Ratio were $(9.72 \mathrm{~g}, 1.07 \mathrm{~g} \& 11 \%)$ in $1^{\text {st }}$ crop, $(9.77 \mathrm{~g}, 1.05 \mathrm{~g} \& 10.75 \%)$ in $2^{\text {nd }}$ crop and $(11.11 \mathrm{~g}, 1.79 \mathrm{~g} \& 16.11 \%)$ in commercial third crop season. The ERR were $41.64 \%$, $50.00 \%$ and $74.51 \%$ in $1^{\text {st }}$, 2nd and $3^{\text {rd }}$ crop respectively. This approach for semidomesticated and commercially exploited Sukinda ecoraces can further enhances their potential because of better inherent performance levels under in situ (Suryanarayana and Srivastava, 2005) over the current basic and commercial stocks maintained ex situ. 


\section{Isolation of different lines/groups of Sukinda}

Sukinda TV cocoons of SG lot harvested from third crop were grouped into four groups/lines on the basis of cocoon colour and weight for assessing the preservation behavior of the harvested cocoons viz. SG-1 (yellow cocoons with cocoon weight $>12 \mathrm{~g}$ ), SG - 2 (yellow cocoons with cocoon weight 10-12 g), SG - 3 (yellow cocoons with cocoon weight $<10 \mathrm{~g}$ ) and SG (grey colour cocoons).

\section{Preservation Behavior}

The preservation behavior was studied for all the four groups in during January-May (Summer). Erratic moth emergence was recorded regularly and the stock was finally screened to assess pupal mortality. The preservation loss details are presented in Table1 (a) \& 1(b).

\section{Table-1(a): Preservation behaviour of different lines of Sukinda TV}

\begin{tabular}{|l|c|c|c|c|}
\hline \multirow{2}{*}{ Particulars } & \multicolumn{3}{|c|}{ Yellow } & SG \\
\cline { 2 - 4 } & SG-1 & SG-2 & SG-3 & \\
\hline $\begin{array}{l}\text { No. of cocoons preserved for } \\
\text { study }\end{array}$ & 788 & 684 & 1602 & 157 \\
No of male moths emerged & $05(0.63)$ & $45(6.57)$ & $73(4.55)$ & $07(4.45)$ \\
(Erratic) & $69(8.75)$ & $60(8.77)$ & $22(1.37)$ & $05(3.18)$ \\
No. of female moths emerged & & & & \\
(Err.) & $74(9.39)$ & $105(15.35)$ & $95(5.93)$ & $12(7.64)$ \\
Total moths emerged (Erratic) & $08(1.01)$ & $22(3.21)$ & $71(4.43)$ & $04(2.50)$ \\
Dead cocoons sorted out & $\mathbf{1 0 . 4}$ & $\mathbf{1 8 . 5 6}$ & $\mathbf{1 0 . 3 6}$ & $\mathbf{1 0 . 1 9}$ \\
Total preservation loss (\%) & & & & \\
\hline
\end{tabular}

Table-2(b): Summer Preservation behaviour of different lines of Sukinda TV

\begin{tabular}{|l|c|c|c|}
\hline \multirow{2}{*}{ Particulars } & \multicolumn{3}{|c|}{ Preservation loss } \\
\cline { 2 - 4 } & SG-1 & SG-2 & SG-3 \\
\hline Cocoons preserved for study & $\mathbf{3 8 5 6}$ & $\mathbf{3 7 3 2}$ & $\mathbf{3 7 7 4}$ \\
\hline No. of male moths emerged(Erratic) & $180(4.66)$ & $186(4.98)$ & $372(9.85)$ \\
\hline No. of female moths emerged(Erratic) & $141(3.66)$ & $215(5.76)$ & $205(5.43)$ \\
\hline Total moths emerged (Erratic) & $321(8.32)$ & $401(10.74)$ & $577(15.28)$ \\
\hline Dead cocoons sorted out & $80(2.07)$ & $84(2.25)$ & $165(4.37)$ \\
\hline Total Preservation loss No. (\%) & $\mathbf{4 0 1}(\mathbf{1 0 . 3 9})$ & $\mathbf{4 8 5}(\mathbf{1 3 . 0 0})$ & $\mathbf{6 8 5}(\mathbf{1 8 . 1 5})$ \\
\hline Seed cocoons left for 1 ${ }^{\text {st }}$ Grainage, 06 & $3455(89.61)$ & $3247(87.00)$ & $3089(81.85)$ \\
\hline
\end{tabular}

*Figures in parenthesis indicate percentage

It was observed that preservation loss ranged between $10.19 \%$ in SG to $18.56 \%$ in SG-2. SG-1 showed preservation loss of $10.4 \%$ while in SG-3 the preservation loss was 
$10.36 \%$ where as the final preservation loss was lowest $10.39 \%$ in SG-1, followed by $13.0 \%$ in SG-2 and $18.85 \%$ in SG-3 group.

Grainage Behaviour of the preserved cocoons was also studied by conducting different grainages the results are presented in the table 2 .

Table-2: Grainage behaviour of different lines of Sukinda TV in $1^{\text {st }}$ Crop.

\begin{tabular}{|c|c|c|c|c|}
\hline \multirow[t]{2}{*}{ Particulars } & \multicolumn{3}{|l|}{ Yellow } & Grey \\
\hline & SG-1 & SG-2 & SG-3 & SG \\
\hline Cocoons processed for study & 706 & 557 & 1436 & 141 \\
\hline Male moths emerged & $101(14.30)$ & 241(43.26) & $1080(75.20)$ & $78(55.31)$ \\
\hline Female moths emerged & $596(84.56)$ & $314(56.37)$ & $348(23.23)$ & $56(39.70)$ \\
\hline Total moths emerged & 697(98.72) & $555(99.64)$ & $1428(99.44)$ & $134(95.03)$ \\
\hline Pairings obtained & $87(86.13)^{*}$ & $245(78.02)$ & $145(41.66)$ & $29(51.78)$ \\
\hline Poor fecundity & $18(20.68)$ & $58(23.67)$ & $41(28.27)$ & $05(17.24)$ \\
\hline Pebrine \% & 15.94 & 14.97 & 16.34 & 8.33 \\
\hline Cocoon /dfl ratio & $13: 1$ & $4: 1$ & $17: 1$ & $6: 1$ \\
\hline Av. Fecundity & 240 & 197 & 178 & 191 \\
\hline Date of initiation of grainage & 24.06 .05 & 23.06 .05 & 23.06 .05 & 27.06 .05 \\
\hline Date of completion of grainage & 14.07 .05 & 14.07 .05 & 14.07 .05 & 13.07 .05 \\
\hline Duration of grainage (days) & 21 & 22 & 22 & 17 \\
\hline
\end{tabular}

*Figures in parenthesis indicate percentage.

A perusal of the data presented in the table indicated that during grainage highest self coupling $(86.13 \%)$ was recorded in SG-1 followed by $78.02 \%$ in SG-2, $41.66 \%$ in SG-3 and $51.78 \%$ in SG. The fecundity ranged from173-301 in SG-1, $132-261$ in SG- 2, $122-197$ in SG-3 and 168-201 in SG. The SG-2 lot showed better cocoon dfls ratio of 3.5: 1.

Second crop Grainage was carried out with 3000 seed cocoons (yellow coloured) of each group viz. SG-1, SG-2, SG-3 and 300 Grey cocoons (SG). The grainage performance is presented in table-3.

Table-3: Grainage performance study of different lines of Sukinda TV in second crop

\begin{tabular}{|c|l|c|c|c|c|}
\hline $\begin{array}{c}\text { Sl. } \\
\text { No }\end{array}$ & \multicolumn{1}{|c|}{ Parameters } & SG-1 & SG-2 & SG-3 & SG \\
\hline 1 & Number of cocoons processed & 3000 & 3000 & 3000 & 300 \\
\hline 2 & Date of Grainage initiation & 25.8 .05 & 25.8 .05 & 25.8 .05 & 26.8 .05 \\
\hline 3 & Emergence Details : Male & $1771(59.03)$ & $1737(57.9)$ & $1597(53.23)$ & $178(59.33)$ \\
\hline 4 & Female & $1222(40.730$ & $1242(41.4)$ & $1356(45.2)$ & $107(35.36)$ \\
\hline 5 & Total & $2993(99.76)$ & $2979(99.3)$ & $2953(98.43)$ & $285(95.00)$ \\
\hline 6 & Couplings obtained & $812(66.44)$ & $691(55.63)$ & $761(56.12)$ & $45(42.05)$ \\
\hline 7 & Poor fecundity & $54(6.65)$ & $72(10.42)$ & $156(20.4)$ & $09(20.0)$ \\
\hline 8 & Moths examined & 50 & 50 & 52 & 26 \\
\hline
\end{tabular}




\begin{tabular}{|c|l|c|c|c|c|}
\hline 9 & Pebrine & Nil & Nil & 3.84 & 3.84 \\
\hline 10 & Number of dfls obtained & 50 & 50 & 50 & 25 \\
\hline 11 & Average fecundity & 242 & 215 & 213 & 203 \\
\hline 12 & Cocoon : Laying Ratio & $3.69: 1$ & $4.34: 1$ & $4.95: 1$ & $6.15: 1$ \\
\hline 13 & Dead cocoons sorted out & $07(0.23)$ & $21(0.7)$ & $47(1.5)$ & $15(5.0)$ \\
\hline 14 & Duration of grainage (days) & 12 & 12 & 12 & 7 \\
\hline
\end{tabular}

The grainage data indicated highest coupling in SG-1 (66.44\%) compared to $55.63 \%$ in SG-2, 56.12 \% in SG- 3 and $42.05 \%$ in SG line. The cocoon-laying ratio was found most effective in SG-1 (3.69: 1) followed by SG - 2 (4.34: 1), SG-3 (4.95: 1), and SG (6.15: 1). Highest average fecundity (242) was recorded in SG-1.While in other lines the fecundity was 215 in SG-2, 212 in SG-3 and 203 in SG group. No pebrine were found in SG-1 and SG-2 lot.

Table-4: Grainage performance of different lines of Sukinda TV in Third Crop

\begin{tabular}{|c|c|c|c|c|c|}
\hline $\begin{array}{l}\mathbf{N} \\
\mathbf{0}\end{array}$ & Parameters & SG-1 & SG-2 & SG-3 & SG \\
\hline 1 & $\begin{array}{l}\text { Number of cocoons } \\
\text { processed }\end{array}$ & 842 & 755 & 1155 & 176 \\
\hline 2 & $\begin{array}{l}\text { Date of Grainage } \\
\text { initiation }\end{array}$ & 23.10 .05 & 23.10 .05 & 23.10 .05 & 24.10 .05 \\
\hline 3 & $\begin{array}{l}\text { Emergence Details : } \\
\text { Male }\end{array}$ & 499(59.26) & $454(60.13)$ & $748(64.76)$ & $104(59.09)$ \\
\hline 4 & Female & $336(39.90)$ & 294(38.94) & $366(31.68)$ & $71(40.34)$ \\
\hline 5 & Total & $835(99.16)$ & $748(99.07)$ & 1114(96.44) & $175(99.43)$ \\
\hline 6 & Couplings obtained & 268(79.76) & 198(67.34) & $293(80.05)$ & $32(45.07)$ \\
\hline 7 & Poor fecundity & $22(8.20)$ & $24(12.12)$ & $52(17.74)$ & $07(21.87)$ \\
\hline 8 & Moths examined & 50 & 51 & 53 & Nil \\
\hline 9 & Pebrine & Nil & $01(1.96)$ & $03(5.66)$ & -- \\
\hline 10 & Number of dfls obtained & 50 & 50 & 50 & -- \\
\hline 11 & Average fecundity & 211 & 199 & 195 & 183 \\
\hline 12 & Cocoon: Laying Ratio & $3.14: 1$ & $3.81: 1$ & $3.94: 1$ & $5.5: 1$ \\
\hline 13 & Dead cocoons sorted out & $07(0.83)$ & $04(0.53)$ & $23(1.99)$ & Nil \\
\hline 14 & $\begin{array}{l}\text { Date of completion of } \\
\text { Gr. }\end{array}$ & 31.10 .05 & 31.10 .05 & 2.11 .05 & 30.10 .05 \\
\hline 15 & $\begin{array}{l}\text { Duration of grainage } \\
\text { (Days) }\end{array}$ & 09 & 09 & 11 & 07 \\
\hline 16 & $\begin{array}{ll}\text { Cocoons } & \text { remained } \\
\text { unemerged } & \\
\end{array}$ & Nil & 03 & 18 & 01 \\
\hline
\end{tabular}

During the said grainage highest coupling $(80.00 \%)$ was recorded both in SG-1andSG-3 followed by $67.34 \%$ in SG-2, 45.07\% in SG. The fecundity ranged from191 -232 in SG-1, 
$175-218$ in SG- 2, $166-212$ in SG-3 and 152-201 in SG. The SG-1 lot showed better cocoon-laying ratio of 3.14: 1 .

It was further observed that the dfl recovery in all grainages was at par with the ruling race Daba TV.

After conducting grainage the rearing experiments with the dfls procured were also performed and the rearing behavior of the different lines was observed which are presented in the table 5 .

Table-5: Rearing Performance of different lines of Sukinda TV in First crop

\begin{tabular}{|c|c|c|c|c|c|}
\hline $\begin{array}{l}\text { Sl. } \\
\text { No }\end{array}$ & Parameters & SG - 1 & SG - 2 & SG - 3 & SG \\
\hline 1 & No. of dfls brushed & 50 & 50 & 50 & 10 \\
\hline 2 & Date of brushing & 16.07 .05 & 15.07 .05 & 14.07 .05 & 12.07 .05 \\
\hline 3 & Average fecundity & 270 & 192 & 189 & 171 \\
\hline 4 & Hatching percentage & 82.25 & 84.00 & 80.00 & 81.00 \\
\hline 5 & Larval weight $(\mathrm{g})$ & 32.85 & 32.13 & 30.98 & 31.00 \\
\hline 6 & Date of spinning & 07.08 .05 & 07.08 .05 & 07.08 .05 & 07.08 .05 \\
\hline 7 & Larval duration (days) & 23 & 24 & 24 & 27 \\
\hline \multirow[t]{3}{*}{8} & Cocoons harvested & 4584 & 4105 & 4080 & 728 \\
\hline & Yellow $(\%)$ & 4461(97.32) & $3947(96.15)$ & $3834(93.98)$ & $277(38.05)$ \\
\hline & Grey $(\%)$ & $123(2.68)$ & $158(3.85)$ & $246(6.02)$ & $451(61.95)$ \\
\hline 9 & Cocoons/dfl & 92.0 & 82.0 & 82.0 & 73.0 \\
\hline 10 & ERR (\%) & 41.00 & 51.00 & 54.00 & 53.00 \\
\hline 11 & Cocoon wt. (g) & 10.12 & 9.61 & 9.27 & 9.27 \\
\hline 12 & Shell wt. (g) & 1.08 & 1.03 & 0.90 & 1.02 \\
\hline 13 & S R (\%) & 10.67 & 10.71 & 9.70 & 11.01 \\
\hline \multicolumn{6}{|c|}{ REELING PERFORMANCE } \\
\hline 1 & Filament length $(\mathrm{m})$ & 454 & 525 & 573 & --- \\
\hline 2 & $\begin{array}{l}\text { Non-breakable } \\
\text { Filament Length (m) }\end{array}$ & 194 & 292 & 370 & --- \\
\hline 3 & Filament Wt. (g) & 0.542 & 0.615 & 0.649 & --- \\
\hline 4 & Filament Denier & 10.74 & 10.55 & 10.18 & --- \\
\hline 5 & Raw Silk \% & 60.03 & 65.20 & 65.85 & --- \\
\hline 6 & Waste \% & 38.62 & 34.79 & 34.14 & --- \\
\hline 7 & Reelability \% & 67.85 & 67.36 & 66.43 & --- \\
\hline
\end{tabular}

The rearing performance of above 4 groups/lines indicated that SG-1 performed better with a yield of 92 cocoons/dfl with lesser colour segregation (yellow: grey: 97.3: 2.7), higher cocoon wt.10.12 g, shell wt. 1.08g. While SG-2 yielded 82 cocoons/dfl with(yellow: grey:: 96.2: 3.8), with average cocoon wt. of $9.6 \mathrm{~g}$, shell wt.1.03 g. Similarly SG-3 yielded 82 cocoons/dfl (yellow: grey:: 93.4: 6.6), with average cocoon wt. 9.27g, shell wt. 0.90g and SG yielded 73 cocoons/dfl(grey : yellow 61.9: 38.1), with average cocoon wt.of $9.26 \mathrm{~g}$, shell wt. $1.02 \mathrm{~g}$.

Second crop: Fifty dfls each of SG-1, SG-2, SG-3 and 25 dfls of SG were brushed for further study. The performance details are as in table- 6 below. 
Table-6: Rearing performance of different lines of Sukinda TV in Second Crop, 2005

\begin{tabular}{|l|l|c|c|c|c|}
\hline S1. & Particulars & SG -1 & SG - 2 & SG - 3 & SG \\
\hline 1 & No. of dfls brushed & 50 & 50 & 50 & 25 \\
\hline 2 & Date of brushing & $05 / 06.9 .05$ & $05 / 06.9 .05$ & $05 / 06.9 .05$ & $05 / 07.9 .05$ \\
\hline 3 & Average fecundity & 242 & 221 & 217 & 203 \\
\hline 4 & Hatching percentage & 85.0 & 83.0 & 85.15 & 81.0 \\
\hline 5 & Larval weight (g) & 27.65 & 26.3 & 25.9 & 26.0 \\
\hline 6 & Date of spinning & 27.9 .05 & 28.9 .05 & 28.9 .05 & 28.9 .05 \\
\hline 7 & Larval duration (days) & 23 & 24 & 24 & 24 \\
\hline 8 & Cocoons harvested & 856 & 768 & 1194 & 235 \\
\cline { 2 - 6 } & Yellow (\%) & $842(98.36)$ & $755(98.30)$ & $1155(96.73)$ & $59(25.10)$ \\
\cline { 2 - 6 } & Grey (\%) & $14(1.64)$ & $13(1.7)$ & $39(3.27)$ & $176(74.90)$ \\
\hline 9 & Cocoons/dfl & 17 & 15 & 24 & 09 \\
\hline 10 & ERR $(\%)$ & 8.32 & 8.37 & 13.0 & 6.0 \\
\hline 11 & Cocoon wt. (g) & 9.69 & 9.58 & 10.11 & 10.32 \\
\hline 12 & Shell wt. (g) & 1.03 & 0.97 & 0.98 & 1.04 \\
\hline 13 & S R $(\%)$ & 10.63 & 10.12 & 9.69 & 10.07 \\
\hline
\end{tabular}

The rearing performance of above 4 groups/lines indicated that SG-3 gave better result only in respect of yield (24 cocoons/dfl) and cocoon wt.(10.11 g), but showed higher colour segregation (yellow: grey: 96.73:3. 27), lower shell wt. ( 0.98g.) resulting least SR 9.69\%. TheSG-1 group yielded 17 with lesser cocoon segregation (yellow: grey:: 98.36: 1.64), with average cocoon wt. of $9.69 \mathrm{~g}$, shell wt.1.03 g and highest SR $10.63 \%$. Similarly SG-2 yielded 15 cocoons/dfl (yellow: grey:: 98.30: 1.7), with average cocoon wt. 9.58g, shell wt. $0.97 \mathrm{~g}$ and SG yielded 09 cocoons/dfl(grey : yellow 74.9: 25.10), with average cocoon wt.of $10.32 \mathrm{~g}$, shell wt. $1.04 \mathrm{~g}$.

Third crop: The SG line was discontinued in this crop due to its consistent higher cocoon colour segregation. Fifty dfls each of SG-1, SG-2and SG-3 were reared in this season for performance assessment basing on which a pure line would be selected for re-introduction in the State. The rearing performance is depicted in table-7.

Table-7: Rearing Performance of different lines of Sukinda TV in Third crop

\begin{tabular}{|l|l|c|c|c|}
\hline SI. & Particulars & SG -1 & SG - 2 & SG - 3 \\
\hline 1 & No. of dfls brushed & 50 & 50 & 50 \\
\hline 2 & Date of brushing & 27.10 .05 & 27.10 .05 & $26-27.10 .05$ \\
\hline 3 & Average fecundity & 206 & 175 & 208 \\
\hline 4 & Hatching percentage & 88.33 & 79.50 & 72.25 \\
\hline 5 & Larval weight (g) & 32.10 & 30.65 & 31.00 \\
\hline 6 & Date of spinning & 16.12 .05 & 16.12 .05 & 16.12 .05 \\
\hline 7 & Larval duration (days) & 42 & 42 & 42 \\
\hline 8 & Cocoons harvested & 4250 & 4100 & 4150 \\
\cline { 2 - 5 } & Yellow (\%) & 97.79 & 98.34 & 98.16 \\
\cline { 2 - 5 } & Grey (\%) & 2.21 & 1.66 & 1.84 \\
\hline 9 & Cocoons/dfl & 85 & 82 & 83 \\
\hline 10 & ERR (\%) & 46.71 & 58.94 & 55.23 \\
\hline
\end{tabular}




\begin{tabular}{|l|l|c|c|c|}
\hline 11 & Cocoon wt. (g) & 11.43 & 10.24 & 11.15 \\
\hline 12 & Shell wt. (g) & 1.52 & 1.46 & 1.54 \\
\hline 13 & S R (\%) & 13.29 & 14.25 & 13.81 \\
\hline \multicolumn{3}{|l|}{} \\
\multicolumn{3}{|l|}{ REELING PERFORMANCE } \\
\hline 1 & Filament length (m) & 711 & 724 & 749 \\
\hline 2 & $\begin{array}{l}\text { Non-breakable Filament } \\
\text { Length (m) }\end{array}$ & 474 & 499 & 326 \\
\hline 3 & Filament Wt. (g) & 0.90 & 0.88 & 0.95 \\
\hline 4 & Filament Denier & 11.40 & 10.99 & 11.45 \\
\hline 5 & Raw Silk \% & 64.51 & 62.22 & 64.26 \\
\hline 6 & Waste \% & 35.49 & 37.78 & 37.74 \\
\hline 7 & Reelability \% & 76.38 & 71.76 & 70.59 \\
\hline 8 & Softening \% & 98.0 & 96.0 & 97.0 \\
\hline
\end{tabular}

The perusal of data indicates that the SG-1 showed better yield of 85 cocoons/dfl followed by 83 cocoons/dfl in SG-3 and 82 cocoons/dfl in SG-2 in this crop .All the lines showed more or less same cocoon colour segregation (yellow: grey: 98: 2). However the ERR (59\%) and SR (14.25\%) are found to be better in SG-2 group followed by ERR (55\%), SR $(13.81 \%)$ in SG-3 group and ERR (48\%), SR (13.29\%) in SG-1.

From the observations made above, it seems that the complimentary parameters noted are closure to each other for all the three lines/groups in this crop and there is no significant difference in their performances. As such selection of a pure line out of the above three groups at this stage is not feasible. However 3856 cocoons of SG-1, 3732 cocoons of SG-2 and 3774 cocoons of SG-3 group were preserved and pure line selection efforts were done in subsequent years.

In all three lines yellow cocoons dominated $(>99 \%)$ the population confirmed the race character. Thus all the three groups were pooled together as a rejuvenated race and the cocoons harvested from the $3^{\text {rd }}$ Crop were preserved for production of basic seeds of the race for further utilization.

\section{Multilocational trial of the isolated line(s) at Mayurbhanj, Dhenkanal at farm and farmers'l evel.}

Multilocational trial rearing of 1065 dfls of the Rejuvenated Sukinda TV was conducted in the $3^{\text {rd }}$ crop under four TRCS levels, including in its in situ conditions (Sukindagarh, the natural abode of the race) and BSM \& TC, Baripada. The performance of the rejuvenated Sukinda TV under Multilocational trial at farmers' level is shown in the table- 8 below. 
Table-8: Rearing performance of Sukinda TV under Multilocational trial at different zones in $3^{\text {rd }}$ crop

\begin{tabular}{|c|c|c|c|c|c|c|}
\hline Particulars & $\begin{array}{c}\text { Sukindagar } \\
\mathrm{h} \\
\text { Jajpur Dist. }\end{array}$ & $\begin{array}{l}\text { Chandua, } \\
\text { Mayurbhanj } \\
\text { Dist. }\end{array}$ & $\begin{array}{c}\text { Niagiri } \\
\text { Balasore } \\
\text { Dist. }\end{array}$ & $\begin{array}{c}\text { Kuliana, } \\
\text { Mayurbhanj } \\
\text { Dist. }\end{array}$ & $\begin{array}{c}\text { BSM\&TC, } \\
\text { Baripada }\end{array}$ & $\begin{array}{c}\text { RTRS } \\
\text {,Baripada }\end{array}$ \\
\hline No. of dfls brushed & 275 & 175 & 295 & 220 & 100 & 150 \\
\hline Date of brushing & $\begin{array}{l}13.10 .06 \\
20.10 .06\end{array}$ & $\begin{array}{l}14.10 .06 \\
16.10 .06\end{array}$ & $\begin{array}{c}9.10 .06 \\
11.10 .06\end{array}$ & $\begin{array}{c}9.10 .06 \\
12.10 .06\end{array}$ & 18.10 .06 & 12.10 .06 \\
\hline Av. Fecundity & 200 & 201 & 190 & 201 & 193 & 201 \\
\hline Hatching percentage & 80.0 & 83.0 & 83.0 & 85.0 & 90.0 & 86.33 \\
\hline Larval wt.(g) & 40.6 & 38.75 & 40.0 & 37.0 & 36.0 & 41.41 \\
\hline Date of spinning & 12.11 .06 & & 18.11 .06 & 8.11 .06 & 17.11 .06 & 9.11 .06 \\
\hline Larval duration(days) & 31 & \multirow{9}{*}{$\begin{array}{l}\text { Crop } \\
\text { failed }\end{array}$} & 41 & 30 & 30 & 29 \\
\hline Cocoons harvested & 8880 & & 13865 & 9580 & 6500 & 10300 \\
\hline Yellow $(\%)$ & 99.00 & & 99.00 & 99.32 & 98.00 & 99.33 \\
\hline $\operatorname{Grey}(\%)$ & 1.00 & & 1.00 & 0.68 & 2.00 & 0.67 \\
\hline Cocoon / dfl & 32 & & 47 & 44 & 65 & 69 \\
\hline ERR\% & 20.18 & & 30.00 & 25.40 & 37.42 & 40.00 \\
\hline Cocoon wt.(g) & 11.94 & & 11.98 & 11.90 & 11.19 & 12.60 \\
\hline Shell wt.(g) & 1.95 & & 1.87 & 1.90 & 1.80 & 2.07 \\
\hline S R \% & 16.33 & & 15.61 & 15.97 & 16.08 & 16.43 \\
\hline
\end{tabular}

Perusal of the data indicates highest yield of 65 cocoons /dfl was recorded at BSM\&TC, Baripada while rearing at one location namely Chandua failed. Cocoon yield in other three locations ranged from 32 to 47 cocoons /dfl. The silk ratio varied from $15.61 \%$ to $16.33 \%$ and the commercial characters were at per at all the places. A rearing with 150 dfls of STV, conducted at RTRS, during the said crop yielded an average of 69 cocoons / dfls with silk ratio of $16.43 \%$.

Preservation, Grainage and Supply of Rejuvenated Sukinda(TV) basic seeds to state department and BSM\&TCs for multiplication and further commercial exploitation

A total of 16081 rejuvenated Sukinda (TV) cocoons harvested in $3^{\text {rd }}$ crop were preserved to supply the rejuvenated Sukinda TV basic seeds to the state TRCSs and BSM \&TCs for multiplication and further commercial exploitation in Orissa. Erratic moth emergence was regularly recorded during the period from January to May.The preservation loss details is given in table-9. It was observed that the total preservation loss was $7.63 \%$ only

Table-9: PRESERVATION LOSS DETAILS OF REJUVENATED SUKINDA (TV)

\begin{tabular}{|l|c|}
\hline \multicolumn{1}{|c|}{ Particulars } & Values \\
\hline Cocoons preserved & 16081 \\
\hline Male moths emerged & $325(2.02)$ \\
\hline Female moths emerged & $245(1.52)$ \\
\hline Total erratic emergence & $570(3.54)$ \\
\hline Total preservation loss & $658(4.09)$ \\
\hline Dead cocoons sorted out & $1228(7.63)$ \\
\hline Seed cocoons left for $1^{\text {st }}$ Grainage'2007 & 14853 \\
\hline
\end{tabular}

Figures in parenthesis indicate percentage. 


\section{Grainage of the pure line of Sukinda TV in First Crop}

The First crop grainage was carried out with 14853 cocoons of Sukinda TV. The grainage detail is presented in table- 10 .

Table-10: Grainage performance of Rejuvenated Sukinda TV in $1^{\text {st }}$ Crop.

\begin{tabular}{|l|c|}
\hline \multicolumn{1}{|c|}{ Particulars } & Values \\
\hline No. of cocoons processed & 14853 \\
\hline Emergence details:Male & $9010(61.0)$ \\
\hline Female & $5760(39.0)$ \\
\hline Total & $14,770()$ \\
\hline Pairings obtained & $5001(86.82)$ \\
\hline Rejection due to poor fecundity & $141(2.82)$ \\
\hline Moths examined & 4860 \\
\hline Rejected due to pebrine & Nil \\
\hline No. of Dfls obtained & 4860 \\
\hline Average fecundity & 211 \\
\hline Cocoons dfl Ratio & $3: 1$ \\
\hline Duration of Grainage(Days) & 29 \\
\hline Cocoons remained unemerged & 83() \\
\hline Dfls supplied & 4560 \\
\hline Dfls utilized for own rearing & 300 \\
\hline
\end{tabular}

First grainage indicated hundred percent moth emergence with $61 \%$ male and $39 \%$ female. A total no. of 4860 dfls was prepared @ 3:1 cocoon dfl ratio. There was no trace of pebrine. The fecundity ranged between 187 to 238 . However the grainage duration prolonged up to 29 days due to erratic rainfall.

Supply of rejuvenated Sukinda (TV) basic seed to state TRCSs and BSM\&TCs for multiplication and further commercial exploitation.

A total of 4560 rejuvenated Sukinda (TV) dfls were supplied as per following details for popularization of the rejuvenated ecorace.

\begin{tabular}{|c|l|c|}
\hline $\begin{array}{c}\text { Sl. } \\
\text { No. }\end{array}$ & \multicolumn{1}{|c|}{ Name of the recipient } & No.of dfls supplied \\
\hline 1 & RTRS, Warrangal (A.P.) & 330 \\
\hline 2 & REC, Purulia (W.B.) & 280 \\
\hline 3 & REC, Bangriposi, Orissa & 400 \\
\hline 4 & PPC, Mangalpur,Sukinda Garh, Dist.Jajpur,Orissa & 1000 \\
\hline 5 & Asst.Director (Seri.), Keonjhar,Orissa & 1000 \\
\hline 6 & $\begin{array}{l}\text { Asstt. Director(seri.),Mayurbhanj,Orissa.(Chandua, } \\
\text { Kuliana and Nilagiri TRCSs) }\end{array}$ & 1550 \\
\hline & \multicolumn{1}{|c|}{ Total: } & 4560 \\
\hline
\end{tabular}

With this experiment a pure line of Sukinda ecorace could be developed which started behaving equally at all the supplied places. This effort with Sukinda ecorace resulted in to the rejuvenation of dying natural treasure of Odisha. 


\section{References:}

1.Raffi, S.M. and T.K. Ramanujam, 2001. Environmentally sustainable rural development in India. Indian J. Environ. Protec., 21: 852-855.

2.Suryanarayana, N. and A.K. Srivastava, 2005. Monograph on Tropical Tasar Silkworm. Central Tasar Research and Training Institute, Central Silk Board, Government of India, Ranchi, India, pp: 1-87.

3.Srivastava, A.K.; Sinha, A. K. and (2002).Present status of tropical silkworm germplasm management. Workshop on Germplasm Management and Utilisation at CSGRC,Hosur,Base Paper,1-12.

4.Srivastava, A.K.; A.K. Sinha and B.R.R.P.Sinha (2003).Descriptor of tropical tasar silkworm ,Antheraea mylitta Drury, 1-9

5. Suryanarayana,N.,A.K. srivastava,2005, Monograph of Tropical Tasar Silkworm, CTR\&TI, Ranchi, India,pp 1-87.

6. Thangavelu,K., K.V.S. Rao and V.K.pandey,2002, wild silkmoth diversity and conservation, Int.J.wild silkmoth silk,7: 89-93 